\title{
LA ESCAPADA (IL SORPASSO, 1962), DÍAS DE VIEJO GOLOR
}

\author{
Emilio Soler \\ Universidad de Alicante
}

Una agobiante tarde sabatina, en la que matábamos el tiempo esperando el partido del Hércules en La Viña del día siguiente, Mario, José Antonio, Enrique y un servidor habíamos quedado para ir al cine. La cita era en el Monumental, Salón Moderno, portada neo-neoclásica y varias filas de escaleras exteriores donde solíamos esperar a las guapitas de turno (que casi nunca llegaban); echaban dos de indios y vaqueros, mis favoritas. Mientras roíamos las típicas pipas que vendían en los dos carritos estratégicamente situados frente al mini bar Penalti, ubicado en los bajos del cine, transcurrían aquellas calurosas tardes a comienzos de los años sesenta. Era un estío alicantino en que el aire acondicionado representaba una quimera con la que soñábamos por entonces y que solamente nos era dado imaginarlo, que no disfrutarlo, en las películas de Rock Hudson y Doris Day.

Mario, siempre con su aureola de pequeño intelectual más o menos rebelde, se empeñó en que nos dejáramos de western y nos fuéramos al Carlos III para visionar una película de la que había leído cosas muy interesantes, La escapada, y que a nosotros, sinceramente, nos olía a tostón. Enrique lo aprobó de inmediato porque de ese mismo director, Dino Risi (19162008), recordaba una película que habíamos visto el verano pasado en el cine de verano Niágara que nos había gustado, sobre todo por la belleza de Gina Lollobrigida, Pan, amor y fantasía (1953). Así que, a pesar de que nos perdíamos a John Ford y a Raoul Walsh, pronto nos pusimos de acuerdo y nos dirigimos a la cercana calle Vicente Inglada, donde estaban las taquillas del cine en el que pasaban La escapada.

A pesar de nuestras primitivas protestas, y las insistentes de John Wayne y Clark Gable, Mario nos convenció de que en la película que nos había propuesto salía mucha música, de esa que nos gustaba a José Antonio y a mí. Había leído en algún lugar, seguro que en el Fotogramas, que la banda sonora del film, con Tony Renis, Domenico Modugno, Edoardo Vianello - Peppino di Capri cantando "Twist a Saint Tropez", era fantástica. Peppino di Capri, para los que no lo sepan, era uno de los rockeros italianos más famosos del momento. Natural de Nápoles, o de sus alrededores, se había hecho famoso en nuestros guateques al interpretar "Roberta" y "Champagne", dos de las baladas más buscadas en el pick-up a la hora crepuscular de nuestros bailes familiares, cuando la música rápida dejaba, inevitablemente, paso a las canciones lentas, lentas, y buscábamos a esa chiquita rubia con melenita y ojos grandes 
que nos tenía embelesado... Atrás, habiendo cumplido con creces su objetivo de calentar ambiente, se habían quedado los rock and roll de Elvis, Johnny Hallyday o el twist en castellano de Enrique Guzmán y los Teen Tops.

El cinema Carlos III, que cerró sus puertas para siempre jamás en el 2001 tras una penosa agonía, resultaba una de las salas más curiosas que uno recuerda al estar emplazada en un estrecho y larguísimo solar enclavado entre las calles Calderón y San Vicente que, anteriormente, había sido un frontón, por las mañanas y tardes, y, por las noches se convertía, como por arte de birlibirloque, en un local de verano (Cinema Río) de los que tanto abundaban en esta ciudad en la década de los sesenta. Ahora, se había transformado en lujosa sala de estreno capaz, decían, de competir con el suntuoso cine Avenida de la Rambla de Méndez Núñez, que también se vio obligado a bajar el telón un poco antes.

Bueno, pues al final, nos preparamos para La escapada. Mario, con su vehemencia habitual, ganó la partida. La película, a la que Riddley Scott rindiera décadas más tarde algo más que un homenaje con su Thelma y Louise (1991), desde un principio nos sorprendió con un ritmo vertiginoso. Bruno Cortona (Vittorio Gassman), de mediana edad, cínico, entre play-boy y fanfarrón, busca desesperadamente un teléfono en una ciudad cerrada a cal y canto durante el caluroso ferragosto romano, tan pesado como el nuestro pero más lejos de la brisa marina del Postiguet.

De repente, mientras se salta las direcciones prohibidas al volante de su descapotable de dos plazas y cuando comienza a desesperar de poder telefonear, descubre en una ventana a Roberto Mariani (Jean Louis Trintignant), un joven tímido y apocado que aprovecha el tórrido mes de vacaciones para estudiar una difícil asignatura de Derecho, la carrera que cursa. Bruno pronto convence a Roberto para que le abra la puerta de su piso y le permita hacer una llamada. De la conversación se pasa a una insistente invitación para que Roberto abandone, a regañadientes, por unas horas los estudios y se vayan a comer a la playa para romper su monótona vida: "déjate llevar".

Sin saber muy bien cómo, Roberto se encuentra embarcado junto a Bruno en una loca aventura de veinticuatro horas siempre a bordo de un descuidado descapotable Lancia Aurelia Sport y en la que, secuencia a secuencia, su lánguida vida va a sufrir un rápido aprendizaje por la comarca de la Toscana y las playas de moda.

La prometida comida en un chiringuito playero pronto produce un nuevo choque en Roberto, ya que es él a quien le toca pagar la factura y, mientras espera a que Bruno duerma la siesta, suponemos que acompañado por la bella camarera que les había servido, se pregunta qué hace él allí, y duda entre marcharse o quedarse.

Bruno, un verdadero encantador de serpientes, conduce a Roberto por una espiral ascendente en la que su juventud y su adolescencia se van a encontrar alteradas en cuanto el compañero accidental de fatigas conoce a los tíos de Roberto, una pareja de ancianos y una tía solterona y cuarentona que envejecen en su mansión campestre. Allí, tras ser recibidos efusivamente por la familia, Bruno, a la chita callando, seduce a la tieta serratiana, de la que Roberto estaba platónicamente enamorado desde su más tierna infancia. Además, avisado por su jovial amigo, descubre que su primo no es hijo de su tío sino del administrador de la finca... En muy pocas horas, toda su añorada infancia se ha venido abajo, se ha derrumbado: "Todo el mundo tiene un recuerdo equivocado de la infancia".

No obstante, y sin tiempo para reaccionar, Roberto se deja llevar por Bruno, que pronto ha encontrado un nuevo motivo para seguir la ruta carretera adelante. En una de las playas 
más chics de aquellos momentos, Bruno recala con su decrépito Lancia en el chalet de su ex esposa. La hija de ambos, interpretada por una jovencísima Catherine Spaak, aparece en escena como prometida de un sesentón muy rico. Bruno se escandaliza hasta cerciorarse de que puede sacar algo de provecho con esa unión algo más que sentimental. Esa misma noche, tan solo habían transcurrido unas horas desde que los dos ya amigos se conocieran en Roma, la antigua mujer de Bruno lo echa de su dormitorio cuando éste la requería y, en un arranque entre dignidad y ridículo, decide despertar a Roberto para irse a dormir a la playa. Al día siguiente, entre bailar el madison, hacer esquí acuático y jugar una partida de cartas, Roberto siente la necesidad de despertar a la vida. Secretamente enamorado de su vecina, a la que tan solo se ha dirigido una vez en la universidad, rompe su timidez y se plantea localizarla en la playa de Viareggio, su lugar de veraneo.

El aprendizaje vital del joven estudiante de Derecho ha sido fulminante. En las pocas horas transcurridas desde que conociera a Bruno, una profunda transformación se ha producido en el carácter de Roberto. De repente, otra forma de vivir se abre ante él merced a las enseñanzas a todo ritmo de su cínico amigo, un vividor partidario a ultranza del carpe diem, de coger la flor dondequiera que esté y en el momento en que ésta se presente. Roberto, ante el entusiasmo de Bruno que cree haber influido poderosamente en su amigo, decide marchar a Viareggio para declararle amor a su joven vecina. Todo parece ir viento en popa cuando los dos amigos, a bordo del inefable Lancia Aurelia, tan protagonista de la película como el estío y los dos intérpretes principales, emprenden las curvas que les van a llevar a la playa de moda para la clase media italiana de la década de los sesenta. Como nuestro Benidorm, vamos.

Digo que todo parece ir sobre ruedas, nunca mejor dicho, cuando, en un adelantamiento a todo riesgo, como todos los de Bruno, que da nombre al film (Il sorpasso), el deportivo se despeña y el play boy, que ha tenido apenas tiempo de saltar, contempla, incrédulo, como sus dos más queridos compañeros, el coche y Roberto, arden en el fondo del acantilado mientras él ha salvado el pellejo...

La tragicomedia escénica se enlaza con la Italia del boom económico de los sesenta filmada por Dino Risi y con guión de su estrecho colaborador y más tarde uno de los grandes directores italianos Ettore Scola. Con su incomunicación familiar al estilo de los filmes de un Antonioni que, con su film El eclipse (1962), recibe un homenaje en el diálogo, con los negocios fáciles entre constructores y políticos de la Democracia Cristiana santificados por la Mafia y la bendición del Vaticano que nos había narrado Leonardo Sciascia y habían filmado Francesco Rosi o Elio Petri. Una película que aventura la emancipación de la mujer, al menos la de las jóvenes; una época fielmente retratada en la que la sociedad de consumo, a pleno ritmo, todavía contrasta con la imagen de la década anterior de los cincuenta, la inmediata al fin de la guerra: la de la miseria de todo tipo, tanto en Italia como en España, retratadas por De Sica y Bardem. Aquellas de familias montadas en scooter con sidecar que filmaban Fellini y Berlanga... Aunque aquí, por estos lares, ya hubiéramos querido disfrutar del sistema democrático del que disfrutaban en Italia. Ellos habían padecido a Benito, pero nosotros seguíamos sufriendo a Francisco.

Una sociedad, aquella de los sesenta, en la que, como aseguraba Gramsci en otras circunstancias históricas, "lo nuevo no había terminado de crecer y lo viejo no había acabado por desaparecer". Como Roberto y Bruno. Como en nosotros, los de entonces aunque todavía las libertades italianas nos quedaran muy lejanas. 
Para nosotros, los de aquí, era la época que nos veíamos obligados a estudiar Magisterio o Perito Mercantil porque en Alicante no había universidad ni asomo de ella. Cuando el Real Madrid era el buque insignia del franquismo y las libertades seguían amordazadas porque el sindicato era único y corporativo y a los partidos políticos democráticos se les perseguía hasta la extenuación. Cuando los tecnócratas del Opus Dei se imponían con su camisa blanca y su corbata de marca a los viejos gerifaltes falangistas de camisa azul y corbata negra, negra, mientras monseñor Escrivá de Balaguer, el fundador de la Obra, se felicitaba diciendo aquello de "nos han hecho ministros". Cuando el histórico Parlamento de la Carrera de San Jerónimo, el mismo que había vibrado con los discursos de Emilio Castelar o Manuel Azaña, se convertía en cómodo asiento de unos procuradores elegidos a dedo y con la presencia más que pintoresca de representantes saharauis y guineanos que demostraban fehacientemente que el rancio imperio español continuaba vivo...

Era también cuando las mujeres casadas no podían tener cuenta bancaria si no disponían del oportuno permiso marital. Cuando el torero Manuel Benítez, el Cordobés, levantaba pasiones por doquier y demostraba que con voluntad y esfuerzo todo se podía conseguir, porque más cornás daba el hambre. Cuando nos sorprendía ver en la película como en aquella cercana y lejana Italia existían máquinas expendedoras de tabaco, aunque no funcionaran demasiado bien.

Cuando, también, las rubias de ojos celestes ataviadas con bikinis, comenzaban a inundar las playas de un Benidorm que se había inventado, o casi, Pedro Zaragoza, y que parecía San Remo por lo del Festival de la Canción. Cuando celebramos con toda pompa y boato los llamados XXV Años de Paz.

Era aquel tiempo cuando descubrimos el seiscientos que, incluso, podríamos pagar a plazos, firmando letras por un tubo y abonándolas, especialmente, con el pluriempleo o el dinero que enviaban nuestros familiares que se había marchado a trabajar a Alemania o a la vendimia francesa. $Y$ sin necesidad de hacernos ricos con las quinielas, que también. Tiempo en el que pudimos comprarnos aquel televisor Zenith monocolor donde podíamos ver Bonanza o Un millón para el mejor sin necesidad de dar la tabarra al vecino que ya lo poseía. Y, también, cuando con la llegada del televisor dijimos adiós al consultorio de Doña Elena Francis, a Diego Valor, Ama Rosa o a Matilde, Perico y Periquín y dejamos de comprar los tebeos de la editorial Maga de Pantera Negra, Apache o Bengala. O los del Capitán Trueno, el primer español que se ligó a una sueca, Sigrid de Thule, sin necesidad de intentarlo, como tantas veces alguno de nosotros en las playas benidormesas y con tan magros resultados.

Cuando este país, ya a finales de los sesenta, con un Régimen moribundo y maloliente por la corrupción (SOFICO y MATESA, por ejemplo) comenzó a cambiar a pesar del terrorismo etarra y las abultadas cifras de parados. El ejemplo francés de mayo del 68 prendió en España, aunque con mucha suavidad. Y a pesar de que la Virgen se apareció al obispo Clemente en El Palmar de Troya advirtiendo de los peligros si volvían socialistas y comunistas, de continuo surgían foros políticos que nos recordaban que otro país era posible. Y las universidades españolas, los que las tenían, aquí de momento ya hemos dicho que no, se convirtieron en nidos de demócratas potenciales que leían los libros de El Ruedo lbérico o revistas como Triunfo y Cuadernos para el Diálogo. Los mismos que marchaban/marchábamos a Perpignan, Ceret o Le Boulou para disfrutar con "El último tango en París" o "Z" y al pasar la frontera, cuando la policía nos preguntaba si teníamos algo que declarar, sonreíamos de forma pícara. Los que diez años después volvíamos de Portugal tarareando "Grandola, vila 
morena", de José Alfonso, tras haber visionado, seguidas para más inri, las dos partes del Novecento (1976), de Bernardo Bertolucci.

Y asistíamos, si la autoridad gubernativa lo permitía, que muchas veces no, a los multitudinarios recitales de Raimon, Al Tall, Elisa Serna, Lluis Llach o José Antonio Labordeta. En una época, en fin, la agónica del régimen franquista, en la que los representantes de la cultura, los intelectuales y los artistas jugaron un papel decisivo. Si el cine español progresista, con Carlos Saura a la cabeza como discípulo aventajado del exiliado Luis Buñuel, consiguió reconocimiento internacional y apoyo a nuestros creadores, los plásticos, como Saura, Tàpies, Arcadi Blasco, Millares o Rivera, contribuyeron con su presencia en las Bienales y Muestras en el extranjero a demostrar que la miseria intelectual del franquismo no había podido con la libertad, siquiera fuera la artística. Y mostraron que en España multitud de creadores jóvenes habían recogido el testigo dejado, entre otros muchos, por Pablo Picasso, Joan Miró o Josep Renau.

Mario, José Antonio, Enrique y un servidor todavía somos amigos. Y seguimos recordando, sin demasiada nostalgia, que conste, aquellos días de viejo color en Alicante, una ciudad que cerraba cines y espectáculos todos los 20 de noviembre, la fecha en que José Antonio Primo de Rivera fue fusilado por la legalidad republicana en la antigua prisión alicantina. Aquellos días en que los cines-terraza de verano se extendían por todos nuestros barrios y nos permitían asistir a un programa doble a módico precio y con la ventaja de poder comerte un bocata de atún mientras sorbías el Tri-Naranjus del Dr. Trigo, a pesar de la incomodidad que suponían las sillas de madera y los mosquitos que no paraban de asediarnos, como los indios a Fort Apache. Cuando en la Semana Santa tan solo nos daban por la tele películas de cristianos y santos, tipo Los Diez Mandamientos (1956) o La túnica sagrada (1953). Cuando mi padre nos tiró de casa por los gritos que dábamos viendo a Mina bailando un charlestón muy sensual en aquel programa musical, mientras esperábamos la conexión con Australia para ver a Manolo Santana en la Copa Davis. Cuando los guateques familiares en la cocina de casa se acababan bruscamente, "antes de que dieran las diez", al hacer su temible aparición la señora de la casa, encendiendo de forma brusca la luz... y, precisamente, en el momento en que empezaba a sonar en el pick-up "Senza fine", de Gino Paoli, nada menos.

Para algunos de nosotros, para un servidor especialmente, la película de Dino Risi significó a mis dieciséis años un choque impactante, muy parecido al que sentí cuando en un programa radiofónico que se llamaba Discomanía ("La cansión más dulse, la que yega al alma y la que yena de alegría...") dirigido por el chileno Raúl Matas, escuché por primera vez una canción de los Beatles, "She loves you", que me llevó a toda prisa a visitar mi tienda de discos favorita.

Con todo eso y por todo eso, algo estaba empezando a cambiar para la gente de nuestra época. Y no solo era cuestión de música o de cine, de actitudes o de modas, se trataba de que toda una generación se estaba preparando para participar en los rígidos destinos de un mundo gerontocrático que, hasta entonces, se había limitado a sonreír despectivamente en principio, y a reprimir después, cuando los más jóvenes buscaban la arena de la playa bajo los adoquines de los bulevares parisinos. 